ISSN $1410-9840$

\title{
PREDIKSI GETARAN YANG DIAKIBATKAN OLEH KERETA API MELINTAS
}

\author{
Agus Margiantono \\ Jurusan Teknik Elektro Fakultas Teknik Universitas Semarang
}

\begin{abstract}
Tapak proyek pembangunan Jalan KA Jalur Ganda Cirebon-Kroya terletak di dua propinsi yaitu Propinsi Jawa Barat dan Jawa Tengah. Dengan adanya jalur Ganda dipastikan akan terjadi peningkatan getaran disepanjang jalur tersebut. Berdasarkan Kep-49/MENLH/11/1996, dampak getaran ada 2 yaitu : dampak getaran untuk kenyamanan dan kesehatan serta dampak getaran mekanik untuk struktur dan bangunan. Disemua titik sampel studi didapatkan semua getaran masih dibawah baku tingkat getaran Berdasarkan Kep49/MENLH/11/1996. Getaran terbesar akibat operasinal Kereta api terdapat disetasiun Kejaksan Cirebon. Perlu di cermat jika 2 kereta melintas Getaran telah melampaui baku tingkat getaran Berdasarkan Kep49/MENLH/11/1996.

Kata Kunci; Jalan KA, Jalur Ganda, Kep-49/MENLH/11/1996, setasiun Kejaksan
\end{abstract}

\section{Pendahuluan}

Tapak proyek pembangunan Jalan KA Jalur Ganda Cirebon-Kroya terletak di dua propinsi yaitu Propinsi Jawa Barat dan Jawa Tengah pada 6 daerah Kota/Kabupaten yaitu dimulai dari Stasiun Cirebon pada Km 219+168 di Kota Cirebon, Kabupaten Cirebon, Kabupaten Brebes, Kabupaten Tegal, Kabupaten Banyumas sampai Km 377+122 di Stasiun Kroya yang ada di Kabupaten Cilacap. Rencana pembangunan jalur ganda rel kereta api lintas Cirebon-Kroya sepanjang 158 km meliputi kegiatan teknis antara lain adalah:

- Pembangunan Alas Jalan Rel (Roadbed) \& Jalur Rel (Track)

- Pembangunan Terowongan (Tunel) sebanyak 2 buah

- Peningkatan 2 buah stasiun

- Pembangunan Jembatan

- Pekerjaan Saluran dan Drainase

- Relokasi Jalan

- Pembangunan Fly over \& under pass

- Pemasangan Sistem Signal dan Telekomunikasi

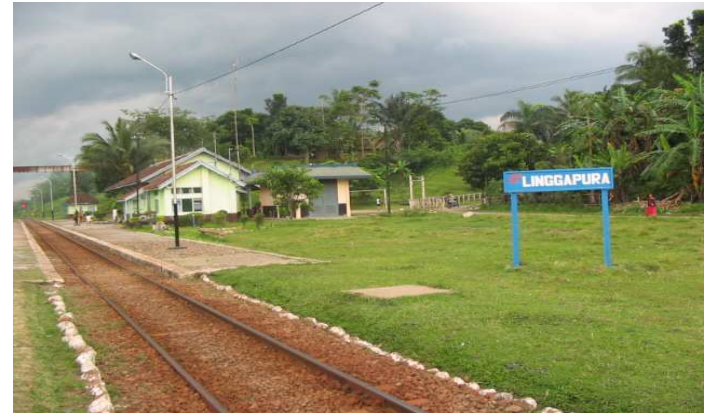

Gambar.1. Salah Satu Titik Sampel Lokasi Pengukuran

\section{Metode Pengukuran}

Berdasarkan Kep-49/MENLH/11/1996, dampak getaran ada 2 yaitu : dampak getaran untuk kenyamanan dan kesehatan serta dampak getaran mekanik untuk struktur dan bangunan. Dampak getaran kesehatan dan kenyamanan diukur simpang getaran (satuan mikron) pada frekuensi $4 \mathrm{~Hz}, 5 \mathrm{~Hz}, 6.3 \mathrm{~Hz}, 8 \mathrm{~Hz}, 10 \mathrm{~Hz}$, $12.5 \mathrm{~Hz}, 16 \mathrm{~Hz}, 20 \mathrm{~Hz}, 25 \mathrm{~Hz}, 31.5 \mathrm{~Hz}, 40$ $\mathrm{Hz}, 50 \mathrm{~Hz}$ dan $63 \mathrm{~Hz}$ yang kemudian dipaparkan pada grafik dan dianalisis untuk mendapatkan kriteria dampak. Untuk 
dampak getaran mekanik yang diukur adalah kecepatan getaran ( satuan $\mathrm{mm} / \mathrm{det}$ ) pada frekuensi $4 \mathrm{~Hz}, 5 \mathrm{~Hz}, 6.3 \mathrm{~Hz}, 8 \mathrm{~Hz}, 10$ $\mathrm{Hz}, 12.5 \mathrm{~Hz}, 16 \mathrm{~Hz}, 20 \mathrm{~Hz}, 25 \mathrm{~Hz}, 31.5 \mathrm{~Hz}$, $40 \mathrm{~Hz}$ dan $50 \mathrm{~Hz}$ yang kemudian dipaparkan pada grafik dan dianalisis untuk mendapatkan kategori dampak.

Berdasarkan hasil pengukuran, diperoleh hasil sebagai berikut :

a. Dampak Getaran untuk Kenyamanan dan Kesehatan

Dari hasil pengukuran simpangan getaran untuk masing-masing lokasi (Tabel 3.12. s/d 3.27 ) yang kemudian digambarkan pada grafik ( Gambar 3.5. s/d. 3.35. ), dapat diketahui semuanya masih berada pada kriteria tidak mengganggu.

b. Dampak Getaran terhadap struktur bangunan

Hasil pengukuran kecepatan getaran untuk tiap-tiap lokasi (Tabel 3.12.s/d 3.27) kemudian digambarkan pada grafik (Gambar 3.6. s/d 3.36.), dapat diketahui bahwa dampak getarannya termasuk dalam kategori A ( tidak menimbulkan kerusakan ).

Dari uraian diatas, dapat disimpulkan bahwa kondisi di daerah sepanjang rencana proyek lintasan ganda Cirebon-Kroya masih berada dibawah baku mutu.

\section{Hasil Pengukuran dan Pembahasan}

Dari pengukuran yang telah dilakukan didapatkan besar getaran untuk kesehatan dan kerusakan bangunan seperti pada tabel dibawah
Tabel.1. Hasil Pengukuran Getaran di Stasiun Cirebon.

\begin{tabular}{|c|c|c|c|}
\hline No & $\begin{array}{l}\text { Frekuensi } \\
(\mathrm{Hz})\end{array}$ & 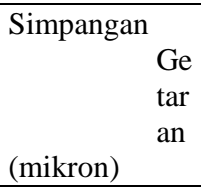 & $\begin{array}{cc}\text { Kecepatan } & \\
& \text { Ge } \\
& \text { tar } \\
& \text { an } \\
(\mathrm{mm} / \mathrm{det}) & \\
\end{array}$ \\
\hline 1 & 4 & 90.44 & 6,02 \\
\hline 2 & 5 & 72.26 & 5,40 \\
\hline 3 & 6.3 & 56.15 & 4,84 \\
\hline 4 & 8 & 39.85 & 4,14 \\
\hline 5 & 10 & 32.34 & 3,92 \\
\hline 6 & 12.5 & 24.44 & 3,71 \\
\hline 7 & 16 & 20.26 & 3,50 \\
\hline 8 & 20 & 16.65 & 3,30 \\
\hline 9 & 25 & 12.17 & 3,18 \\
\hline 10 & 31.5 & 10.58 & 2,84 \\
\hline 11 & 40 & 7.54 & 2,46 \\
\hline 12 & 50 & 5.85 & 2,04 \\
\hline 13 & 63 & 4.69 & \\
\hline
\end{tabular}

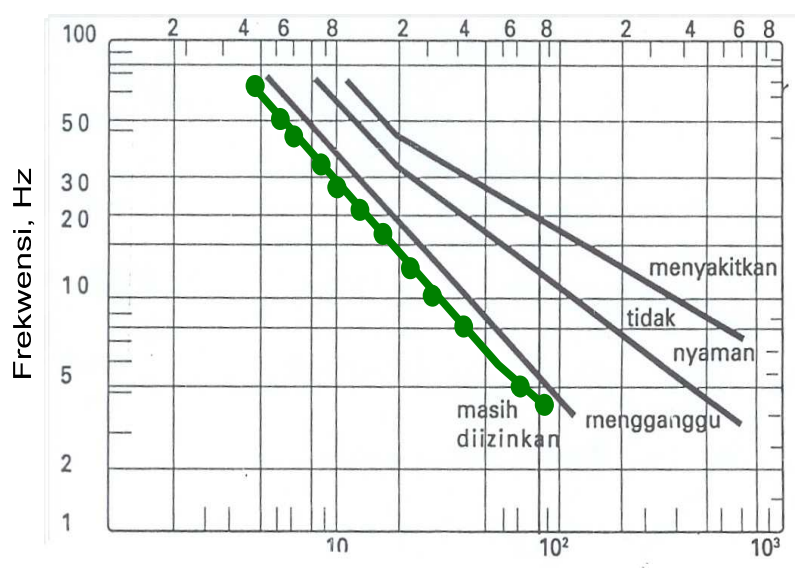

Simpangan Getaran (mikron)

Gambar2. Grafik tingkat getaran untuk kenyamanan dan kesehatan di Stasiun Cirebon (warna hijau)

Keterangan: grafik masih berada di areal masih diizinkan, artinya termasuk kriteria tidak mengganggu. 


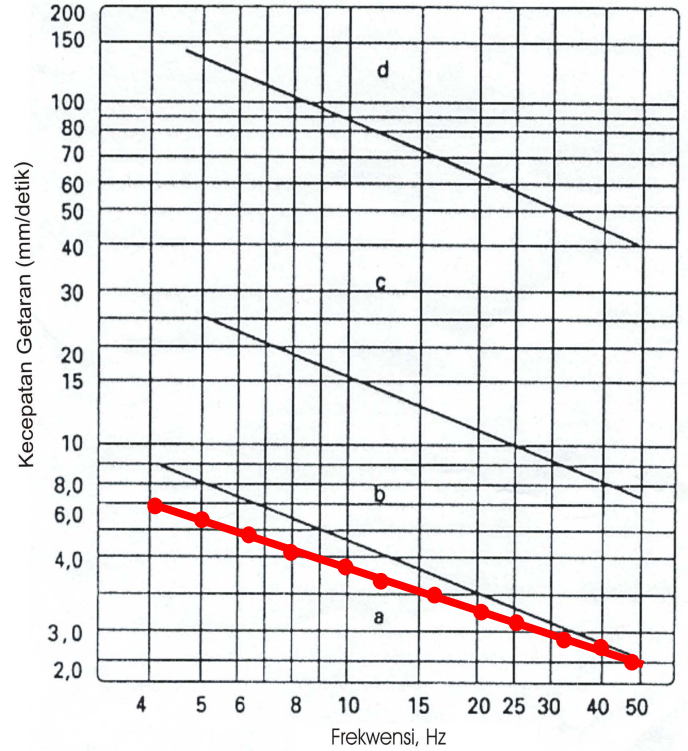

Gambar 3. Grafik Tingkat Getaran Mekanik di Stasiun Cirebon (warna merah)

Keterangan: Grafik yang dihasilkan berada pada areal a, yaitu termasuk kategori $\boldsymbol{A}$ artinya tidak menimbulkan kerusakan.

Tabel.2. Hasil Pengukuran Getaran di MA Syarif Hidayattullah Cirebon

\begin{tabular}{|l|l|ll|l|}
\hline No & $\begin{array}{l}\text { Frekuensi } \\
\text { (Hz) }\end{array}$ & Simpangan & Kecepatan \\
& & $\begin{array}{c}\text { Ge } \\
\text { tar } \\
\text { an } \\
\text { (mikron) }\end{array}$ & $\begin{array}{l}\text { Ge } \\
\text { tar } \\
\text { an } \\
\text { (mm/det) }\end{array}$ \\
\hline 1 & 4 & 61,24 & 2,82 \\
\hline 2 & 5 & 50.06 & 2,56 \\
\hline 3 & 6.3 & 38.18 & 2,33 \\
\hline 4 & 8 & 25,02 & 2,21 \\
\hline 5 & 10 & 15,21 & 2,12 \\
\hline 6 & 12.5 & 12,06 & 2,02 \\
\hline 7 & 16 & 10.41 & 2,01 \\
\hline 8 & 20 & 7,12 & 2,00 \\
\hline 9 & 25 & 5,06 & 1,94 \\
\hline 10 & 31.5 & 4,88 & 1,74 \\
\hline 11 & 40 & 3,94 & 1,54 \\
\hline 12 & 50 & 2,80 & 1,28 \\
\hline 13 & 63 & 1,97 & \\
\hline
\end{tabular}

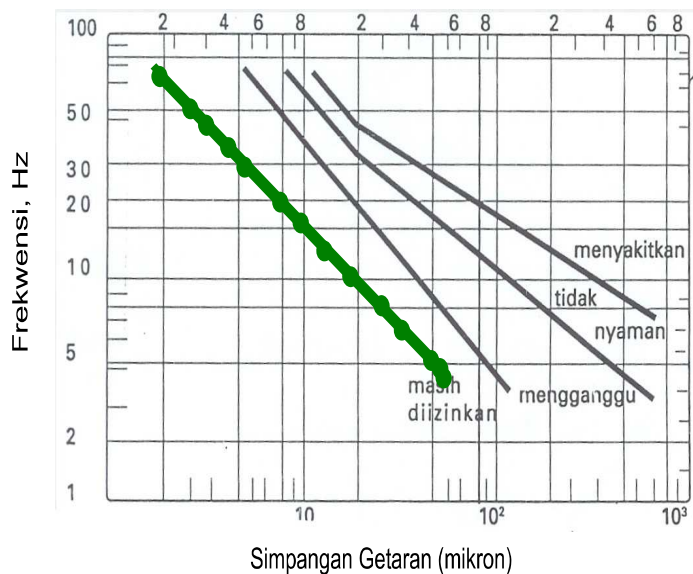

Gambar 4. Grafik tingkat getaran untuk kenyamanan dan kesehatan di MA Syarif Hidayattullah (warna hijau)

Keterangan : grafik masih berada di areal masih diizinkan, artinya termasuk kriteria tidak mengganggu

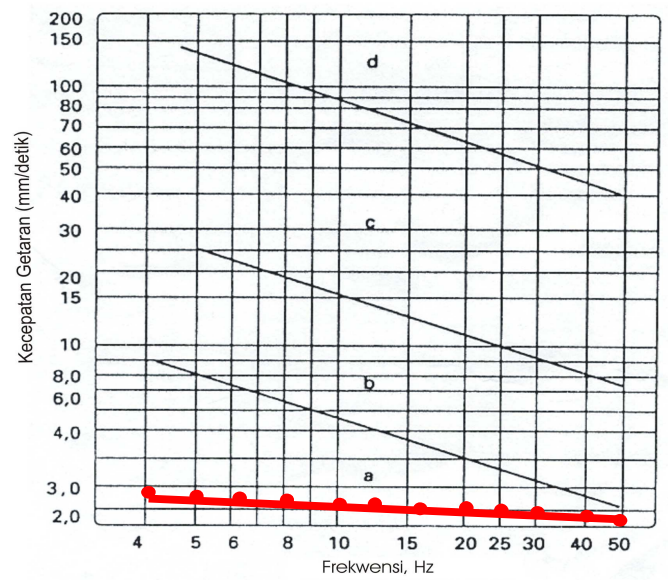

Gambar 5. Grafik Tingkat Getaran Mekanik di MA Syarif Hidayattullah Cirebon (warna merah)

Keterangan : Grafik yang dihasilkan berada pada areal A, yaitu termasuk kategori A, artinya tidak menimbulkan kerusakan 
Tabel.3. Hasil Pengukuran di Pemukiman Penduduk Pulosaren

\begin{tabular}{|l|l|ll|l|}
\hline No & $\begin{array}{l}\text { Frekuensi } \\
(\mathrm{Hz})\end{array}$ & $\begin{array}{l}\text { Simpangan } \\
\text { Ge } \\
\text { tar } \\
\text { an }\end{array}$ & Kecepatan & $\begin{array}{l}\text { Ge } \\
\text { tar } \\
\text { an } \\
\text { (mikron) }\end{array}$ \\
\hline 1 & 4 & 52,50 & 2,24 \\
\hline 2 & 5 & 48,69 & 2,18 \\
\hline 3 & 6.3 & 41,05 & 2,02 \\
\hline 4 & 8 & 35,81 & 2,00 \\
\hline 5 & 10 & 20,57 & 2,00 \\
\hline 6 & 12.5 & 18,95 & 1,98 \\
\hline 7 & 16 & 9,51 & 1,95 \\
\hline 8 & 20 & 7,93 & 1,82 \\
\hline 9 & 25 & 7,04 & 1,74 \\
\hline 10 & 31.5 & 6,12 & 1,56 \\
\hline 11 & 40 & 5,85 & 1,44 \\
\hline 12 & 50 & 4,53 & 1,24 \\
\hline 13 & 63 & 3,11 & \\
\hline
\end{tabular}

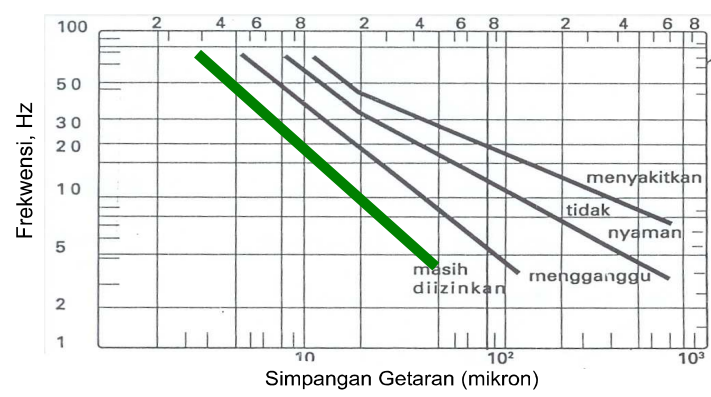

Gambar.6.Grafik tingkat getaran untuk kenyamanan dan kesehatan di Pemukiman Penduduk Pulosaren Pekalipan (warna hijau)

Keterangan: grafik masih berada di areal masih diizinkan, artinya termasuk kriteria tidak mengganggu

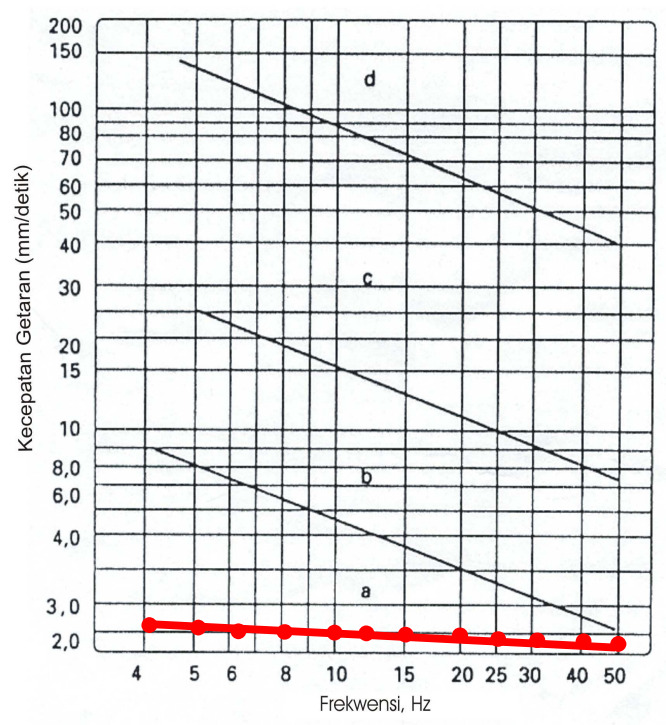

Gambar.7.Grafik Tingkat Getaran Mekanik di Permukiman Penduduk Pulosaren Pekalipan (warna merah)

Keterangan : Grafik yang dihasilkan berada pada areal a, yaitu termasuk kategori $\boldsymbol{A}$ artinya tidak menimbulkan kerusakan.

\section{Simpulan}

- Disemua titik sampel studi didapatkan semua getaran masih dibawah baku tingkat getaran Berdasarkan Kep49/MENLH/11/1996.

- Getaran terbesar akibat operasinal Kereta api terdapat disetasiun Kejaksan Cirebon.

- $\quad$ Perlu di cermat jika 2 kereta melintas Getaran telah melampaui baku tingkat getaran Berdasarkan Kep49/MENLH/11/1996.

\section{DAFTAR PUSTAKA}

Danusaputro H, dkk, 1997, "Pengukuran frekuensi diri dan dampak langsung dari suara speaker pada besaran dinamis Candi Borobudur", Laporan Penelitian 
Danusaputro, H, 2000,"Dampak Pada Bising dan Getaran", Makalah Diklat Propinsi Jawa Tengah.

David Halliday, 1985, "Physics", 3nd edition, John Wiley Sons

F.E. Richard, Jr, 1994, "Vibrations of soils and fondations", Prentice Hall, Inc, Englewood Cliffs, New Jersey.

Badan Pengendalian Dampak Lingkungan, 1996. Himpunan Peraturan di Bidang Pengendalian Dampak Lingkungan,

Sutimin, 1999, "Masalah Vibrasi pada Struktur Elastis", makalah seminar

Sutrisno, 1984, "Fisika Dasar", Penerbit ITB.

Team, 1999, ANDAL Pembangunan Jalur Ganda KA Lintas Cirebon-Kroya, PT Insan Mandiri, Jakarta 